\title{
ANALYTICITY AND CONTEXT-SENSITIVITY. ON GILLIAN RUSSELL'S ACCOUNT OF TRUTH IN VIRTUE OF MEANING
}

\author{
AlFONSO LOSADA \\ Universidad de Buenos Aires \\ CONICET \\ alfonsolosada@yahoo.com.ar
}

\begin{abstract}
SUMMARY: An objection is made to Gillian Russell's (2008) attempt to give an account of analyticity in its metaphysical understanding - that is, that a sentence is analytic just in case it is true in virtue of its meaning. The objection focuses on the semantic aspects of the account, arguing that the kind of context sensitivity envisaged in it ends up yielding the disastrous result that no sentence is analytic in the intended manner. Two possible replies to the objection are analyzed and rebutted.
\end{abstract}

KEY WORDS: semantics, metasemantics, meaning-assignment, character, reference

RESUMen: Presento una objeción al intento de Gillian Russell (2008) de proporcionar una teoría de la analiticidad en su lectura metafísica — es decir, que una oración es analítica sólo en caso de que sea verdadera en virtud de su significado-. La objeción se centra en los aspectos semánticos de la teoría, y argumento que el tipo de sensibilidad al contexto que se propone en la misma termina produciendo el resultado desastroso de que ninguna oración es analítica en el modo buscado. Analizo y rechazo dos posibles respuestas a la objeción.

PALABRAS CLAVE: semántica, metasemántica, asignación de significado, carácter, referente

\section{Metaphysical and Epistemological Analyticity}

A sentence is said to be analytic if it is true in virtue of its meaning. Traditional examples of analytic sentences are conceptual, mathematical and (instances of) logical truths, such as:

(i) All bachelors are men.

(ii) $2+2=4$.

(iii) Either snow is white or it isn't.

(iv) A or not $\mathrm{A}$.

In saying that a sentence is true in virtue of meaning we might mean two things. Following Boghossian, we can distinguish a metaphysical understanding of the notion, from an epistemological one: 
On [one] understanding, "analyticity" is an overtly epistemological notion: a statement is "true by virtue of its meaning" provided that grasp of its meaning alone suffices for justified belief in its truth.

Another, far more metaphysical reading of the phrase "true by virtue of meaning" is also available, however, according to which a statement is analytic provided that, in some appropriate sense, it owes its truth value completely to its meaning, and not at all to the facts. (Boghossian 1996, p. 363)

In the early stages, it seemed that there was an intimate relation between the two readings. ${ }^{l}$ For, a sentence was thought to be analytic if its truth was dependent on its meaning alone. And, if there are sentences that fulfill this condition, one could justifiably come to believe one of these sentences (or the proposition it expresses) independently of outer experience: it would only take examination and comprehension of the meaning of the sentence to determine that it is true. Furthermore, given the latter, analyticity seemed to be very useful in order to account for the a priori knowledge of certain truths.

Quine's attack on the notion (1935, 1951 and 1954) made a huge impact and nowadays many follow him in rejecting it. However, recently, some defenders of analyticity have emerged, though with qualified versions of it. On one side, Paul Boghossian (1996 and 2003) holds that one can sustain an epistemological conception of analyticity, along with its epistemological advantages; but he also holds that this does not commit us to the metaphysical conception. In fact, he rejects the latter for he finds it "of dubious explanatory value and possibly also of dubious coherence" (Boghossian 1996, p. 364).

On the other side, Gillian Russell (2008) has defended the notion in its metaphysical understanding. But, unlike Boghossian, she departs from the epistemological understanding, divorcing the metaphysical feature from the epistemological properties that were once associated with the notion - although she does signal some possibly interesting consequences for justification of beliefs arising from her metaphysical notion.

In this paper, I will be concerned with Russell's account of truth in virtue of meaning, discussing her proposal, focusing on its semantic aspects. The main focus of criticism will be the different

\footnotetext{
${ }^{1}$ Probably the major defender of the notion in contemporary philosophy was Rudolf Carnap (1947, 1950 and 1952)
} 
kinds of context-sensitivity that she presents as a basis for explaining the (lack of) analyticity of the sentences of natural language. I will mostly leave aside sentences of logic and mathematical truths, but I believe an extension of the objection to those domains of discourse can be easily provided. In Section 2, I present Russell's account of analyticity in its modal conception and the kind of meaning involved in it. In Section 3, I present the problem for Russell's proposal, based on considerations regarding context-sensitivity. I will argue that, if certain expressions present sensitivity to a context of introduction, as Russell holds, it can only be so at the expense of a general phenomenon of sensitivity to context of use, in a sense to be explained. The latter has the consequence that no sentence will fulfill the condition of being true in virtue of meaning. In Section 4, I consider two possible replies from the supporter of Russell's view, which will hopefully help us understand better the points from the previous section.

\section{Russell's Account of Analyticity}

According to a widespread view on semantics, advocated by Russell, a declarative sentence is used to express a proposition, which in turn encodes its truth conditions, that is, the conditions that must be satisfied in order for the sentence to be true. Different expressions contribute with different components to propositions, such as properties, particular objects and individuals. Some expressions, such as names and indexicals, are directly referential: they contribute to the propositional content expressed by the sentence in which they appear with the object referred to. A further component of the semantic profile of indexicals and demonstratives is given by a rule for picking out a referent relative to a context of use. Finally, semantic externalism has it that a competent speaker needs not possess knowledge of identifying conditions in order to refer to an object/kind/substance/property. The referential mechanism is external to him and does not depend on his knowledge. (Russell is following here the lead of philosophers such as Kaplan (1989b), Kripke (1980) and Putnam (1975).)

In an attempt to deepen the conceptual progress made by the advocates of such views, Russell distinguishes four senses in which we might talk about an expression's meaning:

- Character: the thing speakers must know (perhaps tacitly) to count as understanding an expression. 
- Content: what the word contributes to what a sentence containing it says (the proposition it expresses).

- Reference Determiner: a condition which an object must meet in order to be the referent of, or fall in the extension of, an expression.

- Referent/Extension: the (set of) object(s) to which the term applies. (Russell 2008, pp. 45-46)

In order to elucidate how a sentence can be true in virtue of meaning, we start by noticing that the semantic value of a sentence depends on two factors: what the sentence means and what the world is like. According to Russell, a sentence is true in virtue of meaning when the meaning of the sentence fully determines its truth value: no matter what state of affairs is considered as a point for evaluating what the sentence says, it will always be the case that the extension of the latter will be True. ${ }^{2}$

Now, given that we have distinguished several aspects or types of meaning, we must ask what is the meaning involved in "truth in virtue of meaning". In the past, the aspect of meaning considered as relevant was that of Content - which in turn makes the world of evaluation the relevant state of affairs for determining the sentence's truth value. Russell notes that this assumption leads to two troublesome consequences, one for the general way of understanding how the value of an expression may be shifted according to the two-factor account advocated by her, and the other regarding the results for an account of analyticity. First, if meaning is understood as content, then the two-factor story does not work for certain expressions, namely, directly referential terms, for we couldn't change their value unless their reference was shifted. Once we settle a content (relative to a referent assignment), there is no way of shifting the expression's value unless we shift its referent. For example, given that proper names are directly referential, the content of "Saul Kripke" is Saul Kripke, its referent. Had "Saul Kripke" meant David Kaplan, it would contribute David Kaplan to the proposition expressed

${ }^{2}$ This characterization of the notion avoids one of the major objections to it, namely, the one that says that the notion makes little sense, for it is a truism that for any sentence $S, S$ is true iff for some $p, S$ means that $p$, and $p$. So, the idea of a sentence being true in virtue of meaning alone is absurd, for it is clearly wrong to think that meaning can determine the truth value of the sentence by itself (Quine 1954, p. 113; Boghossian 1996, pp. 364-365). A response similar to Russell's is explored in Hofmann and Horvath's 2008. 
by every sentence containing it; but this would only be so because the referent would have been shifted, for in this kind of case it is the referent which determines the content. Shifting the world of evaluation won't work either, for these are rigid expressions, designating the same object in every possible world. So, if we wish to keep working in the two-factor story, content is not the aspect of meaning we should focus on. Second, the assumption leads to the collapse of analyticity into necessity. For necessary truths are true in every possible circumstance; hence, given the characterization above, they would be true in virtue of meaning. Now, of course, it would be a hard pill to swallow to accept that sentences such as (v) or (vi), while expressing necessary truths, are also analytic:

(v) Hesperus is Phosphorus.

(vi) Water is $\mathrm{H}_{2} \mathrm{O}$.

On the other hand, identifying analyticity with necessity would lead to the abandonment of certain sentences being analytic because they don't express necessary truths. Such is the case of (vii):

(vii) I am here now.

This sentence does not express necessary truths, though Russell would prima facie like to count it among the sentences which are true in virtue of meaning.

These problematic consequences, though, only follow from the assumption that the aspect of meaning involved is Content, a claim which Russell departs from. It is, she claims instead, in virtue of Reference Determiners that sentences turn out analytic or not. This is the aspect of meaning we must focus on. ${ }^{3}$ For not only will it provide us with a way of making the two-factor account plausible for every expression by allowing us to change the value of the expressions relative to different kinds of contexts as explained below, but it will also enable us to avoid the collapse into necessity, and thus the capacity to account for all the sentences that we would want to count as true in virtue of meaning.

As for the actual reference determiners of different kinds of expressions, Russell provides what she takes to be plausible stories of

${ }^{3}$ Note that reference determiner is an aspect of meaning that ordinary speakers are not required to be knowledgeable of - unlike character. This can be seen as the source of the divorce between this notion of analyticity and the epistemic properties traditionally associated with it. 
how to understand them. Each of these stories highlights the different kinds of sensitivities that reference determiners present. For example, the reference determiner for a proper name picks out the object that played a certain role when the name was introduced. So, if "Hesperus" was introduced by pointing at a bright object in the sky, and saying "Let's call that 'Hesperus", the name will refer to whatever the baptizer demonstrated when saying that in the context of introduction of the name - as Russell labels it. If it was introduced by means of a description (Let "Hesperus" refer to the evening star) it will refer to the object that falls under the description in the context of introduction. Either of these possible ways of introducing a name yields a reference determiner for that name: being the $\mathrm{x}$ such that $\mathrm{x}$ plays such and such a role in the context of introduction of the name.

In the case of predicates such as "bachelor" (purely descriptive predicates), whether the predicate applies to an object is determined by whether or not the object has the properties associated with the predicate (such as being a man and being unmarried, in the case of "bachelor"). These associated properties provide us with the conditions contained in the reference determiner.

For singular indexicals, the referent is determined according to a certain role it plays in the context of utterance. For example, the referent determiner for "I" is: for all $x$, "I" refers to $x$ iff $x$ is the agent of the context of utterance.

Reference/extension determination (and the correlating determination of truth value of a sentence) may be thus sensitive to different kinds of states of affairs. For example, indexical directly referential terms, such as "now", have reference determiners sensitive to the context in which the expression is uttered, that is, they pick out different referents in different contexts of use. But they don't present sensitivity to contexts of introduction (nor to contexts of evaluation, since they are directly referential). Proper names, on the other hand, get their referents fixed in the context in which they were introduced. Had that context been different in the relevant respect, that is, had another object or individual played the role of the object that the speaker was intending to name when she introduced the expression, the referent of the expression would have been different. But they are not sensitive to context of use or to context of evaluation. Finally, the extension of a predicate, in general, is sensitive to the state of affairs with respect to which we evaluate it. A given object might fall under it in the actual world but not in another possible world. But predicates do not present sensitivity to context of introduction and context of use. 
Consequently, Russell holds that the truth of a sentence may be relative to a context of evaluation, or a context of utterance, or a context of introduction - where the or is intended inclusively. That is due to different reasons: had the context of introduction or context of use been different, different propositions might have been expressed by the sentence; and had the context of evaluation been different, objects or individuals might have possessed (or not) a property ascribed to them.

Acknowledging these types of sensitivity, Russell's definition of analyticity runs as follows:

Truth in Virtue of Meaning: A sentence $\mathrm{S}$ is true in virtue of meaning just in case for all pairs of context of introduction and context of utterance, the proposition expressed by $\mathrm{S}$ with respect to those contexts is true in the context of evaluation. ${ }^{4}$ (p. 56)

Given the stipulations above about reference determiners, sentences turn out analytic or not according to this definition and to the behavior of the expressions' reference determiners. Consider:

(1) All bachelors are man.

(1) is true in virtue of meaning. Even though the extensions of both predicates may vary in different contexts of evaluation, the extension of bachelor is, let's grant, a subset of the extension of men. Given that the referent determiners of the expressions are not sensitive to context of introduction or context of utterance, the proposition expressed by the sentence will turn out true with respect to all pairs of context of introduction and utterance.

(2) I am here now.

(2) is true in virtue of meaning because the expressions "I", "here" and "now" refer to the agent, the place and the time of the context of utterance, respectively. Given that their reference determiners are not sensitive to context of introduction, and that (following Kaplan) genuine contexts are those in which the agent is located at the time, place and world of evaluation of the context of utterance, the sentence is always true with respect to that context of evaluation.

Other sentences are true under the condition that the terms contained in them have referents:

${ }^{4}$ Where "the context of evaluation" is the context of evaluation contained in the context of utterance. 
(3) Hesperus is Hesperus.

If the reference determiner for the name "Hesperus" succeeds in picking out something in the context of introduction, since the reference determiners for both occurrences of "Hesperus" are identical, they will pick out the same object. The sentence will come out true relative to every context, since "Hesperus" is not sensitive to context of utterance or to context of evaluation.

Finally, other sentences are not true in virtue of meaning even under the assumption of the terms referring. For example:

(4) Hesperus is Phosphorus.

Given that the reference determiners for "Hesperus" and "Phosphorus" are sensitive to context of introduction, there could be a context relative to which the referent determiner of, say, "Hesperus" picks out Mars and the sentence comes out false. Note that this example illustrates the point regarding the non-collapse of analyticity into necessity mentioned above.

So far, I have spelled out Russell's proposal in the fundamental aspects that will be the center of discussion in the next section. The focus of my objection will be, roughly, the idea that some expressions have sensitivity to something akin to a context of introduction, while others don't. However, before we move on, it is necessary to emphasize that Russell wishes to distinguish this modal characterization of analyticity from a stricter, more metaphysical one, which is not subject to vagaries of substantive modal facts that could make it the case that intuitively synthetic sentences turn out analytic. For, if a sentence is not sensitive to context of introduction and context of utterance - that is, no component expression of it has a reference determiner which is sensitive to those contexts, and the sentence expresses a necessary truth-, it would turn out analytic, even when intuitively it is not. ${ }^{5}$ Russell provides a second definition of analyticity based on the idea that we can analyze sentences into a (logical)

\footnotetext{
${ }^{5}$ Russell's invites us to consider the case of a modal hyper-realist who believes as a matter of metaphysical fact that "The morning star is the evening star" expresses a necessary truth; that is, that in each of the possible worlds that there are, the morning star and the evening star are the same object. Given that the reference determiners of the two pure descriptions appearing in the sentence are not sensitive to context of introduction or to context of utterance, the sentence will turn out true relative to each context of utterance and of introduction; hence it would count as true in virtue of meaning, that is, analytic. This is a wrong result, for we wouldn't want to consider that sentence as an analytic one - even from the hyper-realist point of view, I believe (p. 39 and p. 69).
} 
subject and a (logical) predicate component, and then ask ourselves if the reference determiner of the first contains or excludes the reference determiner of the second (p. 100). This tracks the strict notion of analyticity, one that is not subject to substantive modal facts.

I will be working, though, with the first, modal characterization that we have discussed. My main reason for doing so is that it is a conception that makes use of common and widely spread tools from philosophy of language, and in that sense becomes accessible from a generally shared conceptual scheme. However, by doing so, I believe I will also be pressing on Russell's strict conception of analyticity, for two reasons. First, Russell wants to sustain that all analytic sentences in the strict sense are analytic in the second, modal sense (p. 81). So, if we prove, as I'll try to do, that no sentence can be analytic according to the modal definition, this would pose a very unwelcome result for Russell's view in general, namely, that no sentence is strictly analytic. Second, and even if one wants to amend the previous point by dropping the link between the two definitions, the strict conception also makes use of the notion that I will challenge: reference determiner. If the considerations made below regarding the latter are sound, then Russell's strict notion of analyticity will also fail, for, as we will notice in due time, no sentence will fulfill that condition either.

\section{The Problem: Generalized Context-Sensitivity}

As we saw, Russell's modal conception of analyticity relies on distinguishing several aspects of meaning and holding that it is in virtue of what she calls reference determiners, and their sensitivity to different kinds of contexts, that sentences turn out analytic or not. My main concern with Russell's notion of reference determiner is that, in developing it, the sort of conditions that are taken to be relevant for reference determination vary, which becomes problematic for the account of analyticity in Russell's terms. Arguably, for example, an indexical expression such as "here" imposes the condition that the referent must be the place where the expression is being uttered. But also arguably that depends on the fact that the expression came to have a given rule of use associated to it. That in turn depends on primary practices by which speakers used a word with certain intentions in mind. How are we to restrict our condition among all these factors of reference determination? Reference determiners are defined as follows: 
A reference determiner for an expression is a non-circular condition, such that any object which meets it satisfies the expression and does so in virtue of meeting that condition. If there are other non-circular conditions, then the reference determiner is the one in virtue of which the others all hold. (p. 98)

Hence, the reference determiner for "Hesperus", according to Russell's fictional story of her favoured reference-fixing account, is:

$R D$ ("Hesperus"): $\mathrm{x}$ must be the bright spark in the evening sky in 1845 which was noticed by the man who introduced "Hesperus", to which he intended the name to refer.

Other conditions do not satisfy the definition, because they are either circular, such as

$R D$ ("Hesperus")': $x$ must be the referent of "Hesperus".

or they are conditions on being the referent of "Hesperus" in virtue of the fact that $\mathrm{RD}$ ("Hesperus") is a condition on being the referent of "Hesperus", such as:

$R D($ "Hesperus")": $x$ must be the referent of "Phosphorus". (p. 96)

As Russell herself considers, one possible objection to her view is that, in trying to elucidate truth in virtue of meaning, she appeals to facts that lay outside of semantics, that is, outside of a theory of meaning (p. 66). For when her examples are taken into consideration it seems that reference determiners are not always aspects of the semantic profile of an expression. If we compare the case of indexicals with that of proper names, the point seems to put pressure on Russell's account. For, arguably, the reference determiners of indexicals are part of their meaning, given that indexicals only come to express a given content relative to a context of utterance. The reference determiner captures how this reference-determination is carried out in each context: there is, following Kaplan, a linguistic convention, a rule that determines the content of the expression relative to a context, which constitutes the meaning of the expression (Kaplan 1989b, p. 523). The condition an object must satisfy according to such rules in order to be the referent of the expression in a context provides the reference determiner. Proper names, on the contrary, are not sensitive to features of the context in which they are uttered. Once 
they are given a referential meaning, the name expresses the same content in every context - which, according to the direct reference theory, is identical to its referent. The semantic facts concerning proper names, the ones that lie in a theory of meaning, seem to be thus exhausted by their reference assignment. But the historical facts regarding how a name comes to have a referent lie outside of the semantic enterprise; they are part of the metasemantics (Kaplan 1989a, pp. 573-574).

Russell's reference determiners, in the latter case, appeal to these metasemantic facts; for they are intended to capture the contingency involved in the fact that a given expression (proper name) comes to denote something in the context in which it was introduced into the language, but might have had a different referent as its meaning, had the facts of that context been different. Russell holds an analogous view regarding natural kind predicates, such as "water". In this case, the reference determiner of the expression captures the fact that a sample of a different kind could have been the intended referent of the speaker who introduced the term by pointing and stating: "Let's use the word ' $\mathrm{N}$ ' to refer to the substance that has the same underlying structure as that stuff". Had XYZ been the structure of the sample pointed at in the context of introduction of the term "water", then "water" would have referred to XYZ. Again, these are facts concerning how the expression came to mean what it does. However, Russell doesn't consider that the appeal to metasemantic features is a problem, and embraces the idea that reference determiners can belong to metasemantics in some cases. Even if this makes us refrain from referring to the phenomenon at hand as "true in virtue of meaning", "this is not to say that we are not talking about exactly the same phenomenon" (p. 68).

But I believe Russell dismisses the point too quickly and too easily. For, it does make a difference whether reference determiners are informed by semantic facts or by metasemantic facts. It seems that what lies in the heart of Russell's account of proper names and natural-kind terms is that their referential content is given to them by a referential intention involved in the first link of a communicative chain in virtue of which further uses of the expressions causally connected to each other get to refer to the same thing. The condition a reference determiner for such expressions must capture is then: being the individual or a sample of the substance which is the object of that original referential intention. But things could have turned out such that the referent or extension could have been something else instead. So, reference determiners for such expressions are sensitive 
to contexts of introduction. I take it that these considerations are to some extent accepted, at least under the framework in which Russell's proposal is presented. However, I believe further specifications of these facts (such as Russell's fictional story of the introduction of "Hesperus" mentioned above) cannot be a part of what we take as the basis for building a theory of meaning, unless they are somehow justified.

Now, every expression has a metasemantic story underlying the attribution of its meaning. And we can start playing with such stories until we get a condition on the referent of the expression in metasemantic terms. For example, let's take the case of an indexical. Arguably, indexicals were introduced into language in order to make reference to objects/individuals/places/times that played a salient role in the context in which speakers used language. By introducing an indexical expression into language, speakers exploited one such role and stated (perhaps implicitly) a rule of use that depended on it. So, any object that would be referred to by that word would have to satisfy such a role in the context. Given this story (which may be simplifying but I don't believe it involves any great deal of fiction) a reference determiner for "I" could be:

$R D$ ("I"): being the object that satisfies the condition imposed by the use-rule of "I".

Another story could be told about the metasemantics of a predicate such as "bachelor". Introduced to denote a property possessed by individuals who possessed other properties, a reference determiner for "bachelor" could be:

$R D$ ("bachelor"): having the properties associated with "bachelor".

Note that such conditions are not circular, although they are less specific than the ones obtained once the relevant aspects in them are filled - that is, once the rule for "I" and the associated properties of "bachelor" are determined. Nor do they hold in virtue of other conditions holding; they rather seem prior to the ones obtained when those facts are spelled out.

I would like to point out, before moving on, that I'm not claiming that these metasemantic stories are in any sense complete or justified in a solid manner. I do think they have some plausibility, due to the fact that they are built upon arguably justified assumptions concerning the semantic properties of the type of expression they involve 
- that is, the role-relative nature of indexicals and the attachment of associated properties to descriptive predicates. ${ }^{6}$ However, any refinement of such stories will have to make room for the fact that words came to have their specific semantic properties contingently, and therefore recognize that they could have had others instead, and that is what matters for our discussion.

The previous considerations generalize the moment we notice that what underlies these examples is the question: what is it in virtue of which an expression has a given referent/extension? Well, a very simple and plausible account of this issue was developed by Robert Stalnaker in his two-dimensional framework, in which the value of an expression depends on the facts in two ways: first, there are facts that determine what the content of the expression is. Second, the facts about the world determine the extension of the expression, given that it expresses what it does (Stalnaker 1978 and 2006). One can represent this dependence through a two-dimensional framework of possible-worlds semantics, in which every expression is associated with two intensions. The first intension ranges over worlds considered as contexts of use (or, as it is often put, worlds considered as actual) and the second one over contexts of evaluation (or worlds considered as counterfactual). Contexts of use are contexts in which a token of a word, an orthographic type, is uttered. The content of the latter depends on the semantic and contextual features of that context. Contexts of evaluation are the standard worlds that the content expressed by an expression takes as input to deliver an extension. This leaves us with double context sensitivity, which we can call primary and secondary context sensitivity. Primary context sensitivity is open to metasemantic variations in general: it is due to the fact that an expression came to mean what it does that (in a context of use) it expresses the content it does. But those facts (and the ones of the context of use) could have been different, making it possible for an expression to express a different content whether because it meant something different from what it actually means, or because in a context of use different from the actual one it picked out different objects in the world.

In sum, this two-dimensional framework captures the sensitivity of reference both in semantic and metasemantic terms: given what an expression means, reference or extension depends on some features

${ }^{6}$ One could go radical and vary these features as well. But in this context, it is better to allow for a basic restriction, as we are following Russell in her treatment of names and natural kind terms which includes it. 
of contexts of utterance and of evaluation. But the picture goes a step backwards and states that reference is sensitive to the fact that the expression means what it does - a fact which could have been different. For example, in the case of an indexical expression, the facts that determine what the expression contributes to a proposition are, on the one hand, certain semantic facts (namely, that the expression has a given semantic profile - a character) and, on the other, that in the context where it is uttered a given individual satisfies the condition encoded by those semantic facts. Given that indexicals are directly referential terms, and thus rigid designators, no matter which is the world of evaluation, the referent picked out will be the same in each world as the one picked out in the context of use.

In the case of a description, such as "The president of the richest country", the value will depend, first, on the semantic fact that the expression has a given semantic profile (which will in turn depend on the semantic profiles of the component expressions), and, second, on who is the person that satisfies it. In different possible worlds, different individuals will be picked out by that description.

In the case of a proper name, the two facts on which reference is dependent are intimately related. For, according to the direct reference theory, the semantic facts associated with proper names are referential facts. Of course, there was some process by which a name acquired a referent, but such a process is none other than the one through which a semantic profile was assigned to it. Had those facts been different, had the name named something else instead, then the semantic facts regarding the name would've been different. ${ }^{7}$ And, given that names are directly referential expressions, once the referent is determined, it will remain identical across different worlds of evaluation.

Finally, and more generally, the truth-value of a proposition will depend, first, on the identity of the proposition expressed by a given sentence. This is determined by semantic facts - that is, the facts regarding what the expressions mean - and contextual facts in the case of indexical expressions. And second, it will depend on what the world is like in the relevant respects, that is, on whether what the proposition says is the case or not relative to the world:

We need two dimensions since we start with the fact that the truth value of a proposition (at least a contingent proposition) depends on

${ }^{7}$ One could argue that there are further semantic facts associated with a proper name, such as being a directly referential term (Recanati 1993). But that is not an aspect that would do any useful work for an account such as Russell's. 
the facts. But since the identity of the proposition expressed in a given utterance also depends on the facts, the truth value of the utterance will depend on the facts in two different ways: first, the facts determine what is said; second, the facts determine whether what is said is true. (Stalnaker 2006, p. 295)

I contend that if we are to allow for primary context-sensitivity for proper names and natural kind terms we must be relying on some general picture of what it takes for these expressions to have a given referent, such as Stalnaker's. The facts that we can extract from that picture can then be cashed out in terms of the reference determiner for the expressions under consideration. But, if we are going to rely on a picture that allows primary context sensitivity, this should be so unrestrictedly - unless, of course, some other reason is provided for not doing so. According to such a picture, reference determiners can be understood in metasemantic terms and, as we saw, comply with Russell's definition of what reference determiners are. Following Russell, in giving the examples for such metasemantic reference determiners, I kept fixed at least some aspect of the expressions' type; with such a restriction in mind, we can think of reference determiners for different kinds of expressions as specifications of the following general condition on reference or extension:

$R D$ ("e"): being the object such that it fulfills the conditions of the semantic type associated with "e".

However, once we recognize the generality of primary contextsensitivity, that is, sensitivity of reference or extension with respect to the context of meaning assignment, which Russell considered only as applying to some expressions, reference determiners are now open to sensitivity to context of introduction in general. But, if this is the case, no sentence will meet the condition of being true in virtue of meaning; hence, no sentence will be analytic. For, had the word "bachelor" been associated in a given context of introduction with the properties of being a female and being unmarried, the sentence

(1) All bachelors are men.

would have been false relative to that context of introduction and some context(s) of utterance and evaluation. Analogous results would arise by shifting the meaning of "all". Or consider Russell's example involving indexicals: 
(2) I am here now.

Had the metasemantic facts been different, "here" could have meant what "there" actually means, or have a different contextrelative condition attached to it. But then, relative to the context of introduction in which this holds, the sentence would have a meaning such that it would turn out false in some context(s) of utterance (and evaluation).

In conclusion, given that every expression can be thought to have primary context-sensitivity, every expression could have meant something different from what it actually means, even if we keep the semantic properties of the expression's type fixed. If we are to appeal to such context-sensitivity, an account of truth in virtue of meaning in Russell's terms looses any plausibility as a way of capturing metaphysical analyticity in its modal conception (which in turn poses a challenge to the strict conception, as noted before). Paraphrasing Stalnaker, to say that a sentence is true in virtue of meaning in that sense would be to say that "the sentence would express a truth whatever it meant, and that notion, of course, will have no application". ${ }^{8}$

Moreover, I would like to point out that the previous remarks will also be problematic for Russell's strict notion of analyticity in their own right. That is due to the fact that, if reference determiners can be conceived in metasemantic terms across the board, it is hardly the case that the reference determiner for one expression will contain or exclude that of another (contrary to Russell's contention). For there is nothing in the metasemantic version of the reference determiner for "bachelor" - RD("bachelor") - spelled out above which ensures that the reference determiner of any other expression will be either contained in or excluded by it. There are just not enough semantic facts at this level for doing that. Hence, sentence (1) cannot be said to be analytic in the strict sense either. Similar considerations apply to sentence (2) and, I believe, to any other allegedly analytic sentence.

\section{Two Possible Replies}

In this final section, I will consider two possible replies from a supporter of Russell's account of analyticity.

\footnotetext{
${ }^{8}$ Stalnaker was actually making the point against an account of apriority in terms of the two-dimensional model (Stalnaker 2003, p. 199).
} 


\subsection{Restriction of Context-Sensitivity}

One could raise a worry at this point: Russell claims that proper names and natural kind terms are sensitive to context of introduction, in the sense that their reference determiners are such that, if you hold them fixed, had environmental conditions been different in the relevant respect when they were introduced (that is, had the context of introduction been different) they would have referred to something different than what they actually refer to. So, to start with, one might ask: are you claiming that all words are in essence like natural kind terms or proper names? Well, yes and no. Yes in the following sense: one can summarize the remarks of the previous section in the following way:

- It is a semantic fact that expression $e$ means $\mathbf{m}$.

- It is a metasemantic fact that expression $e$ came to mean what it does in virtue of the process of meaning-assignment which presumably involves some practice $\mathbf{P}$ in circumstance $\mathbf{C}$. Had things been different in the relevant respects, $e$ might have meant something other than $m$, say, $\mathbf{m}^{\prime}$.

So, just like proper names and natural kind terms, every expression's semantic value is sensitive to a process of meaning assignment. By the latter I'm not referring to anything as specific as what goes on in a baptism or introduction of a natural kind term. It is rather a way of generalizing the idea that terms came to express what they do in some way or another, depending on practices taking place in certain circumstances in a community of speakers, guided by certain interests and goals of communication, as was briefly illustrated above with the examples for the indexical "I" and the predicate "bachelor".

Now, all words are not in essence like proper names and natural kind terms; for things could have been different in the metasemantic field if either $P$ was different or $C$ was different. Perhaps proper names and natural kind terms can be thought to be sensitive to shifts in the environmental circumstances $C$ (as Russell does). Given that most expressions are nowhere near a baptismal or environmentrelative mode of introduction into the language, variation in metasemantic facts, for them, are most plausibly variations in the practice $P$ involved in the process of meaning assignment; for example, in the assignment of associated properties or of conditions dependent on context-relative-roles. 
A supporter of the analyticity account could then complain: it is only relative to contexts of introduction which vary in their environmental circumstances that reference determiners are sensitive. That is required by the account of proper names and natural kind terms: due to the fact that they are introduced in a context where a causal relation with the environment takes place, their reference determiners can be sensitive to it. Other expressions are not sensitive in this way, perhaps because in their history of coming to mean what they do, there is not even a context of introduction, as understood here, to begin with. Reference determiners are only sensitive to contexts of introduction in this restricted sense.

Of course, it is quite difficult to imagine that every expression is introduced into the language in a specific context by a stipulating description or by pointing at some instance of what is to be expressed by that expression. In other words, given the characterization of contexts of introduction in terms of the role they play in the introduction of certain expressions (a baptism by which a speaker names an object, or a natural kind), that kind of context is not suited to play a role in the metasemantic story of other expressions. But, to start with, the notion of context of introduction and the reference-determining mechanism that relates to it are aspects for which Russell does not provide any argumentation in order to insert them into the semantic theory. Rather, they come as a stipulation of what might be the case. Before providing examples of what reference determiners would look like, she states: "I will assume a theory (often a simplified version of my current favorite theory) of reference determination for the different kinds of expression, and show which sentences would turn out to be true in virtue of meaning on those assumptions" (pp. 57-58).

She then goes on to state the assumptions according to which, as we mentioned above, reference determiners can be sensitive to context of utterance (in the case of indexicals) or context of introduction (proper names and natural kind terms) or context of evaluation (most predicates). But this is where Russell should get more precise on the reference-fixing facts and on the aspects of meaning (understood in a broad sense) that she's going to put at the basis of her analysis of truth in virtue of meaning. A first, weaker reason to demand this is the fact that reference-fixing mechanisms for proper names or natural kind terms are not a settled issue. It could be agreed that an externalist, causal account is to be preferred to an internalist, descriptive one - perhaps mainly due to the objections presented by Kripke to the descriptive theory of reference in Naming and Necessity. But if the notion of reference de- 
terminer is to play a crucial role in further theorizing, one would expect greater precision on what these external, causal facts are. Russell, on the contrary, settles for a potentially adequate (and maybe even fictional) account of them. Now, if we are setting the whole topic aside, because we consider that this is not a proper part of the semantic enterprise, maybe we could settle for an intuitive story of how these facts might go, without the need to spell them out in a precise manner. This seemed to be Kripke's position when presenting his causal story for explaining how names can refer to objects without the mediation of a descriptive content which the object had to satisfy in order to be the referent of the name (Kripke 1980, p. 96). On the contrary, Russell should give a precise account of them, if she is to use them in the way she does.

A second, more important reason for demanding a solid justification before introducing them into further theorizing is that, if we are going to restrict primary context-sensitivity to context of utterance and context of introduction in the stipulated manner, this should be because our semantic theory provides us with grounds for doing so. It should not be the case that the restriction comes from what we are trying to explain. Is there any semantic, philosophical reason for allowing such variation in some cases but not others? Or is it just a trick we are pushing into our semantic theory in order to account for the notion of truth in virtue of meaning? Why not consider a generalized sensitivity in the lines of Stalnaker's model, in which every expression's referent/extension is sensitive to the first dimension of context-dependence, which captures the metasemantic aspects? When we change the referent of the name (or kind term) we change the semantic facts associated with it. So, in this framework, it seems arbitrary to restrict the permission of variation of semantic facts to some expressions but not others. This holds, once again, unless we consider that while shifting the features of the context of introduction, we are still keeping some aspect of the meaning of proper names and natural-kind or mass terms fixed - namely, their reference-fixing descriptions. That is, one could say that, for example, variation by which the clear liquid that runs in rivers, fills lakes, and quenches thirst is XYZ is allowed because at some level that description is what the term "water" means; but shifting that aspect of meaning should not be allowed. The problem with this is that we should expect a good account of what such descriptions are, presented in a systematic and solid manner. Unfortunately, such descriptions are hard to find beyond some toy-examples or without 
assuming very simplified or fictional reference-fixing mechanisms; and those who do try to get at them are still debating the issue. ${ }^{9}$

In sum, restricting primary context-sensitivity to some expressions should not be an easy move to make. For it should be grounded in something, so to speak, previous to the account of truth in virtue of meaning; it should be, I believe, something that stems from the theory of meaning itself. But, as argued in Section 3, the differences one might encounter in the metasemantic stories corresponding to each kind of expression don't seem to be sufficient to make some of them, but not others, primarily sensitive in a relevant way. In any case, it's up to the supporter of Russell's view to show that the contrary holds.

\subsection{Meaning Attribution}

Russell considers an objection according to which: "Since all expressions are introduced at some time or other, shouldn't it always, or at least very often, be the case that what they apply to depends on what the world was like when they were introduced?" (p. 153).

As stated, the objection is quite similar to the one I presented in Section 3. But that, as we saw, was just a rough presentation that helped towards the general point. However, let's move forward into Russell's reply, leaving those remarks aside for the moment. Russell considers an example, with respect to the connective " $\&$ ", in which someone writes a truth-table on a black-board, and pointing at it says:

(5) Let " $\&$ " express the truth-function represented by that truth table.

Had there been a different truth table written on the board, the connective would have expressed a different truth-function. But, according to Russell, this is not a context relative to which the reference determiner for " $\&$ " is sensitive. It's a context in which a different reference-determiner is attributed to the connective. The reference determiner for " $\&$ ", the condition objects must meet to fall under its extension, is: "\&" applies to a pair of truth-values just in case they are both true. In the example, the person who utters (5) states the conditions for the correct application of "\&", with the truth table on the blackboard playing a secondary, instrumental role of showing what these conditions are.

\footnotetext{
${ }^{9}$ Some attempts can be found in García-Carpintero (2006), Jackson (1998), and Pettit (2004).
} 
I think Russell is making here some further assumptions about meaning attribution that can be challenged. First, aren't Russell's contexts of introduction contexts whereby a reference determiner is also attributed to a name or a natural kind term? If the reference determiner is dependent, for example, on the means of the baptism by which the name is introduced, what happens if we vary this condition? Suppose that, in introducing the name "Hesperus", the individual carrying out the baptism had stated: "Let 'Hesperus' refer to the body next to the evening star". By introducing the name by that means, let's suppose, he referred to Mars. Or imagine a context in which the speaker introduces the name by pointing and saying: "Let's call that "Hesperus'." In the actual context of introduction, the utterance was accompanied by a demonstration (the pointing) directed towards Venus. But, in a different context of introduction, the demonstration could have been directed towards Mars. Reference determiners are sensitive to such contexts of introduction, because the specific condition attached to them varies in both cases, and this is a way of explaining how it is possible that "Hesperus is Phosphorus" could have been false relative to a pair of context of introduction and context of utterance (hence, not true in virtue of meaning). What is wrong with explaining things this way? And if there's nothing wrong with it, then again, why should we restrict ourselves, allowing change in meaning attribution (in this case, attribution of conditions on reference) in some cases and not allow it relative to other cases?

On the other hand, Russell's example of introduction of a connective is at most a fictional stipulation regarding the way a meaning might have been attributed to it. Arguably there are other ways (perhaps more plausible ones) of accounting for that attribution. For example, what if we take an Implicit Definition approach to the subject? Here is how Boghossian states the picture: "According to Implicit Definition, the logical constants come to have a particular meaning by our conventionally stipulating that certain sentences (or inferences) involving them are to be true" (Boghossian 1996, p. 381).

"\&", for example, comes to mean what it does in virtue of our assigning the truth-value True to some sentences, such as: "If A, and B, then A \& B". But, it looks like in this case the reference determiner is dependent on such stipulation in a way that it is not on Russell's example. For we don't give a direct account of what it takes for two truth-values to fall under the extension of " $\&$ " (and use some truth-table written on a board as an aid to express that). We rather give the connective a meaning according to which, if two sentences are true, then they fall under its extension. But that 
meaning could have been different, had the sentences involving the connective that were stipulated to be true were other (or had the same sentences been stipulated to be false). And that is a substantial part of meaning attribution that has effects on the conditions for the correct application of the connective.

Now, I'm not claiming that this process of introduction of the connective " $\&$ " is in a better position than Russell's truth-table on a blackboard story in the sense of being a better explanation of how this meaning attribution took place (though I actually believe it is). But I don't think it is my job to give the proper account of meaning attribution for different expressions (maybe the mere task strikes me as a nearly impossible one). I'm just pointing out that we cannot make further theorizing to elucidate other notions - in our case, analyticity - based on fictional assumptions or allegedly intuitive restrictions regarding meaning assignment, context sensitivity and conditions on reference. It is Russell who needs to give us a precise explanation of such facts.

To sum up this last section, I believe Russell's rejection of the possibility of primary context-sensitivity generalizing to other expressions is dependent on assumptions about reference fixing and meaning attribution, which are at most in need of clarification. Until further argumentation, I don't see any principled way of putting a restriction to it.

\section{Concluding remarks}

Gillian Russell presents an account of metaphysical analyticity based on the thesis that the aspect of meaning that plays a role in "truth in virtue of meaning" is that of reference determiner. Focusing on Russell's modal conception of analyticity I have argued that the latter notion is not suited to do the job Russell expects it to do. I also indicated how these arguments present problems for Russell's strict notion of analyticity. In order to account for the intuitive data concerning the analyticity of sentences, reference determiners shift between semantic and metasemantic interpretations of the conditions an object must meet to be the referent or fall under the extension of an expression. But the context-sensitivity alluded to (sensitivity in terms of metasemantic facts) is a general phenomenon, as Stalnaker pointed out. Unless we are given independent semantic reasons for restricting it in the way Russell does, we should not base our account of truth in virtue of meaning on it; for that would be to mould the 
conceptual scheme on the basis of which we are intending to give the account, by means of the phenomenon we are trying to elucidate.

\section{REFERENCES}

Boghossian, P.A., 2003, "Epistemic Analyticity: A Defense", Grazer Philosophische Studien, vol. 66, no. 1, pp. 15-35.

—_, 1996, "Analyticity Reconsidered", Noûs, vol. 30, no. 3, pp. 360391.

Carnap, R., 1952, "Meaning Postulates", Philosophical Studies, vol. 3, no. 5 , pp. 65-73.

- 1950, "Empiricism, Semantics and Onotology", Revue Internationale de Philosophie, vol. 4, pp. 20-40.

—_, 1947, Meaning and Necessity: A Study in Semantics and Modal Logic, reprinted by University of Chicago Press, 1988.

García-Carpintero, M., 2006, "Two-Dimensionalism: A Neo-Fregean Interpretation", in M. García-Carpintero and J. Maciá (eds.), Two-Dimensional Semantics, Oxford University Press, New York.

Hofmann, F. and J. Horvath, 2008, "In Defense of Metaphysical Analyticity", Ratio, vol. 21, no. 3, pp. 300-313.

Jackson, F., 1998, "Reference and Description Revisited", Philosophical Perspectives, vol. 12, pp. 201-218.

Kaplan, D., 1989a, "Afterthoughts", in J. Almong, J. Perry, and H. Wettstein (eds.), Themes from Kaplan, Oxford University Press, New York.

, 1989b, "Demonstratives: An Essay on the Semantics, Logic, Metaphysics, and Epistemology of Demonstratives", in J. Almong, J. Perry, and H. Wettstein (eds.), Themes from Kaplan, Oxford University Press, New York.

Kripke, S.A., 1980, Naming and Necessity, Blackwell, Oxford.

Pettit, P., 2004, "Descriptivism, Rigidified and Anchored", Philosophical Studies, vol. 118, no. 1, The Two-Dimensional Framework and Its Applications: Metaphysics, Language, and Mind, pp. 323-338.

Putnam, H., 1975, "The Meaning of 'Meaning'", in Mind, Language and Reality: Philosophical Papers, vol. 2, Cambridge University Press, Cambridge.

Quine, V.W.O., 1954/1965, "Carnap and Logical Truth", in The Ways of Paradox and Other Essays, Random House, New York.

* I wish to thank Justina Díaz Legaspe and Nicolás Lo Guercio for discussion on previous versions of this paper. I am also very grateful to two anonymous referees for this journal for their insightful comments. Funding for research was provided by the Consejo Nacional de Investigaciones Científicas y Técnicas of Argentina in the form of a Graduate Fellowship and by New York University in the form of a Fondazione Internazionale Premio Balzan Fellowship 2012. 
Quine, V.W.O., 1951, “Two Dogmas of Empiricism", Philosophical Review, vol. 60 , pp. $20-43$.

— 1935/1965, "Truth by Convention", in The Ways of Paradox and Other Essays, Random House, New York.

Recanati, F., 1993, Direct Reference: From Language to Thought, Basil Blackwell, Oxford.

Russell, G., 2008, Truth in Virtue of Meaning. A Defence of the Analytic/Synthetic Distinction, Oxford University Press, New York.

Stalnaker, R., 2006, "Assertion Revisited", in M. García-Carpintero, and J. Maciá (eds.), Two-Dimensional Semantics, Oxford University Press, New York, pp. 293-309.

— 2003, Ways the World Might Be. Metaphysical and Antimetaphysical Essays, Oxford University Press, Oxford. , 1978, "Assertion", in P. Cole (ed.), Syntax and Semantics, vol. 9, Academic Press, New York, pp. 315-332.

Received: May 13, 2013; revised: March 6, 2014; accepted: April 24, 2014. 